DOI: $10.20961 /$ jpscr.v3i2.21924

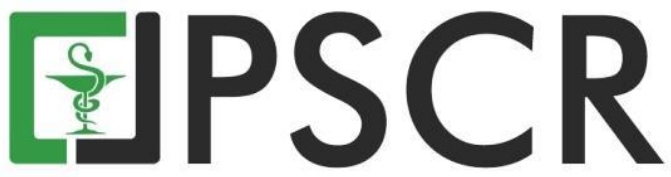

\title{
Skrining Fitokimia dan Aktivitas Antioksidan Ekstrak Etanol Daun Katang-Katang (Ipomoea Pescaprae. L) dari Pulau Lombok Nusa Tenggara Barat
}

\author{
Dahlia Andayani ${ }^{1 *}$ dan Rizki Nugrahani1 \\ ${ }^{1}$ Program Studi DIII Farmasi, Fakultas Fakultas Ilmu Kesehatan, Universitas Nahdlatul Wathan Mataram, NTB \\ *email korespondensi : dahlia_andayani@ymail.com
}

\begin{abstract}
Abstrak: Katang-katang (Ipomoea Pescaprae L.) merupakan jenis tanaman merambat yang biasa digunakan oleh masyarakat suku sasak sebagai obat tradisional untuk mengobati sengatan ubur-ubur. Penelitian ini dilakukan untuk mengetahui kandungan metabolit sekunder dan aktivitas antioksidan daun katang-katang dari pantai tanjung karang lombok sehingga dapat dikembangkan menjadi obat herbal yang berkhasiat sebagai antiinflamasi dan aman dikonsumsi jangka panjang. Skrining fitokimia dilakukan secara kualitatif dan aktivitas antioksidan in vitro ekstrak etanol daun katang-katang menggunakan Metode DPPH dengan vitamin C sebagai pembanding. Ekstrak etanol daun katang katang dibuat dalam bebarapa konsentrasi yaitu 10, 50, 100, 150, 200 dan $250 \mu \mathrm{g} / \mathrm{ml}$. Hasil penelitian menunjukkan bahwa ekstrak etanol daun katang katang dari pulau lombok mengandung flavonoid, alkaloid, saponin dan tanin. Persen penghambatan radikal bebas meningkat sesuai dengan peningkatan konsentrasi yaitu konsentrasi $10 \mu \mathrm{g} / \mathrm{ml}$ memiliki persen penghambatan terendah sebesar $28,02 \%$ dan konsentrasi $250 \mu \mathrm{g} / \mathrm{ml}$ memiliki persen perhambata tertinggi $91,30 \%$. Ekstrak etanol daun katang katang mampu menghambat radikal bebas dengan nilai $\mathrm{IC}_{50} 46,774$ Hasil ini menunjukkan aktivitas antioksidan yang kuat tetapi masih lebih rendah dari vitamin $\mathrm{C}$ yang memiliki $\mathrm{IC}_{50}$ sebesar -0,29.
\end{abstract}

Kata kunci: Katang-katang; Antioksidan; DPPH; Fitokimia

Abstract. Phytochemical screening and antioxidant activity of leaves ethanol of Katang-

Katang (Ipomoea Pescaprae L.) from Lombok Island West Nusa Tenggara. Katang-katang (Ipomoea Pescaprae L.) is a type of vines commonly used by the sasak tribe as a traditional medicine for treating jellyfish stings. This research was conducted to determine the secondary metabolite content and antioxidant activity of katang-katang leaves from the Tanjung Karang Lombok Beach. Phytochemical screening was carried out qualitatively and in vitro antioxidant activity of ethanol extract of katang-katang leaves using DPPH method with vitamin $\mathrm{C}$ as a comparison. Ethanol extracts of katang katang leaves were made in several concentrations of 10, $50,100,150,200$ and $250 \mu \mathrm{g} / \mathrm{ml}$. The results showed that ethanol extract of katang katang leaves from Lombok Island contained flavonoids, alkaloids, saponins and tannins. Percent inhibition of free radicals increased according to the increase in concentration. The concentration of $10 \mu \mathrm{g} / \mathrm{ml}$ extract had the lowest inhibition percentage of $28.02 \%$ and the concentration of $250 \mu \mathrm{g} / \mathrm{ml}$ extract had the highest percentage of $91.30 \%$. Ethanol extract of katang katang leaves was able to inhibit free radicals with $\mathrm{IC}_{50}$ values 46,774 . These results showed strong antioxidant activity but still lower than vitamin $\mathrm{C}$ which $\mathrm{IC}_{50}$ of -0.29 .

Keywords: Ipomoea pescaprae L.; Antioxidant; DPPH; Phytochemicals 


\section{Pendahuluan}

Pulau lombok merupakan pulau yang terkenal dengan wisata pantai yang mendunia seperti pantai senggigi dan pantai Kuta. Sepanjang jalan di daerah pantai yang berpasir putih banyak ditemukan tanaman liar yang tumbuh menjalar di pinggir pantai, tanaman ini berbunga seperti terompet dan dikenal dengan nama tapak kuda atau katang-katang (Ipomoea Pescaprae L.). Sesuai dengan tempat tumbuhnya ternyata tanaman ini secara empiris digunakan untuk mengobati para penduduk atau wisatawan yang tersengat ubur-ubur dan bulu babi ketika bermain dipantai. Khasiat daun katang katang yang diremas dan ditempelkan ditempat sengatan bisa menghilangkan nyeri dan bengkak akibat racun bulu babi dan ubur ubur.

Beberapa penelitian yang pernah dilakukan sebelumnya yaitu Tanaman ini dapat digunakan untuk mengobati peradangan, nyeri, kolik, gangguan diuresis, dan nyeri pada penyakit gonore (Philippi, 2010 cit De Jeses et al. , 2000). Katang katang juga dapat dimanfaatkan sebagai sumber antioksidan alami karena mampu mengambat radikal bebas (Kathiresan, 2014). Aktivitas hepatoprotektif pada kondisi diabetes juga dilaporkan oleh (Suhasini, Elanchezhiyan and Babby, 2014) hasil yang dilaporkan menunjukkan kemampuan ekstrak katang katang mengembalikan kadar antioksidan endogen seperti superoksid dismutase, malondialdehid, dan katalase pada hewan uji. Aktivitas herba katang-katang sebagai antinoiceptik dan antialergi ((Vieira, et al. 2013), antiinflamasi (Pongprayoon, 1991), antibakteri (Anandhi \& Ushadevi, 2013), Antitumor (Mag et al., 2015). Ipomoea Pes caprae L. memiliki kandungan fitokimia yaitu eugenol, Phytol, asarone, unecanonoic acid, phenol (Anandhi and ushadevi, 2013), kandungan metabolit sekunder lainnya alkaloid, flavonoid, steroids, triterpen, tanin, dan senyawa fenolik (Matunog \& Bajo, 2013). Cardic glykosida, antraquinon (Anandhi \& Ushadevi, 2013).

Penelitian ini merupakan penelitian pendahuluan dengan tujuan untuk mengetahui kandungan fitokimia dan aktivitas antioksidan tanaman katang katang dari Pulau Lombok yaitu dari pantai Tanjung Karang Kota Mataram yang akan dikembangkan sebagai obat herbal yang aman dikomsumsi jangka panjang. Pentingnya penelitian ini dilakukan karena Indonesia merupakan negara sub tropis yang memiliki tanaman obat yang belum dieksplorasi secara maksimal. Salah satu tanaman yang belum tereksplorasi adalah tanaman katang katang yang secara empiris memilki khasiat untuk mengobati berbagai jenis peradangan. Dari studi literatur yang sudah dilakukan data khasiat analgetik, antiinflamasi, fitokimia dan antioksidan tanaman katang katang dari Indonesia belum pernah dilaporkan. (Sejauh ini belum ada data kuantitatif $\mathrm{IC}_{50}$ tanaman katang katang sehingga penelitian ini perlu dilakukan untuk mengetahui kekuatan 
ekstrak etanol daun katang katang dari pulau lombok dalam menghambat radikal bebas sehingga bisa dijadikan sebagai salah satu sumber antioksidan alami.

\section{Metodologi Penelitian}

\subsection{Alat dan bahan}

Alat yang digunakan adalah Spektrofotometer Biobase, Evaporator, timbangan analitik, pipet mikrometer, alat alat gelas. Bahan yang digunakan adalah daun katang-katang dari pantai Tanjung karang Kota Mataram, etanol 70 \%, DPPH sigma,Kloroform, amonium hidroksida, asam sulfat,asam klorida,pereaksi dragendorf, pereaksi meyer dan amil alkohol.

\subsection{Preparasi sampel uji}

Herba katang-katang diperoleh dari pantai tanjung karang kota mataram. Bagian tanaman yang digunakan adalah daun. Pengambilan daun dilakukan pada pagi hari sekitar jam 10.00 11.00 WITA. Daun dibersihkan kemudian dipotong kecil $\pm 0,2 \mathrm{~cm}$ dengan menggunakan pisau kemudian dikeringkan menggunakan sinar matahari. Maserasi dilakukan selama 4 hari untuk memperoleh rendeman ekstrak yang maksimal (Matunong \& bajo, 2013), hasil rendaman disaring menggunakan kertas whatman dan dilakukan penguapan etanol menggunakan evaporator. Sisa air diuapkan di atas penangas air dan disimpan selama satu minggu di dalam lemari pendingin suhu $5^{\circ} \mathrm{C}$.

\subsection{Skrining Fitokimia ekstrak daun katang-katang Ipomoea Pescaprae L. menggunakan} metode Harbone (Selvam and Acharya, 2015)

\subsubsection{Uji Alkaloid}

Sebanyak 0,1 gr simplisia dilarutkan dalam $10 \mathrm{ml} \mathrm{CHCl}_{3}$ (kloroform) dan 4 tetes $\mathrm{NH}_{4} \mathrm{OH}$ kemudian disaring dan filtratnya dimasukkan kedalam tabung reaksi tertutup. Ekstrak $\mathrm{CHCl}_{3}$ dalam tabung reaksi kemudian dikocok dengan ditambah 10 tetes $\mathrm{H}_{2} \mathrm{SO}_{4} 2 \mathrm{M}$, sampai terbentuk 2 lapisan. Lapisan asam yang berada di atas dipisahkan ke dalam tabung reaksi yang lain dan ditambahkan preaksi meyer yang menghasilkan endapan warna putih sedangkan penambahan pereaksi dragendorff yang akan menimbulkan endapan warna merah jingga.

\subsubsection{Uji Saponin}

Sebanyak 0,1 gr serbuk ekstrak dimasukkan kedalam gelas piala kemudian ditambahkan $10 \mathrm{ml}$ air panas dan dididihkan selama 5 menit. Setelah itu, disaring dan filtratnya digunakan sebagai larutan uji. Filtrat dimasukkan kedalam tabung reaksi tertutup kemudian dikocok selama 
\pm 10 detik dan dibiarkan selama 10 menit, ditambahkan $1 \mathrm{ml}$ HCL 2M. Adanya saponin ditunjukkan dengan terbentuknya buih yang stabil.

\subsubsection{Uji Tannin}

Sebanyak 0,1 gr serbuk ekstrak ditambahkan dengan $10 \mathrm{ml}$ air panas, dididihkan selama 5 menit dan disaring. Sebagian filtrat yang diperoleh ditambahakan dengan larutan $\mathrm{FeCl}_{3} 1 \%$. Hasil positif ditunjukkan oleh terbentuknya warna hijau kehitaman.

\subsubsection{Uji Flavonoid}

Sebanyak 0,1 serbuk ekstrak dimasukan kedalam gelas piala kemudian kemudin ditambahkan $10 \mathrm{ml}$ aquades dipanaskan sampai mendidih selama 5 menit. Setelah itu, disaring dan filtratnya digunakan sebagai larutan uji. Filtrat dimasukkan ke dalam tabung reaksi lalu ditambahkan pita $\mathrm{Mg}, 1 \mathrm{ml} \mathrm{HCl}$ pekat dan $1 \mathrm{ml}$ amilalkohol kemudian dikocok dengan kuat. Uji positif flavonoid ditandai dengan terbentuknya warna merah, kuning atau jingga pada lapisan amilalkohol.

\subsection{Uji antioksidan ekstrak etanol daun katang katang Ipomoea Pescaprae L.}

Uji aktivitas antioksidan in vitro dilakukan menggunakan metode DPPH (1,1- diphenyl-2picryl hydrazyl) pada panjang gelombang $500 \mathrm{~nm}$. Serbuk ekstrak ditimbang dan dilarutkan menggunakan metanol, diencerkan menjadi beberapa konsentrasi yaitu 10, 50, 100, 150, 200 dan $250 \mu \mathrm{g} / \mathrm{mL}$. 2,5 ml sampel dari beberapa konsentrasi tersebut ditambahkan DPPH sebanyak 1 $\mathrm{ml}$ dengan konsentrasi $0,5 \mathrm{mM}$, kemudian diinkubasi selama 30 menit. Kontrol positif yang digunakan sebagai pembanding yaitu vitamin C (Anwar, 2015). Aktivitas antioksidan dinyatakan sebagai persen inhibisi radikal DPPH yang dihitung dengan rumus (Kathiresan, 2014):

$\%$ Inhibisi $=\left(\left(\mathrm{A}_{\mathrm{U}}-\mathrm{A}_{\mathrm{A}} / \mathrm{A}_{\mathrm{DPPH}}\right)\right) \times 100 \%$

Keterangan: $\mathrm{A}_{\mathrm{U}}=$ absorbansi $2,5 \mathrm{ml}$ sampel uji yang ditambah $1 \mathrm{ml} \mathrm{DPPH}$

$\mathrm{A}_{\mathrm{S}}=$ absorbansi $2,5 \mathrm{ml}$ sampel uji yang ditambah $1 \mathrm{ml}$ etanol

$\mathrm{A}_{\mathrm{DPPH}}=$ absorbansi 2,5 $\mathrm{ml} \mathrm{DPPH}$ 0,5 $\mathrm{mM}$ ditambah $1 \mathrm{ml}$ etanol

\section{Hasil dan Pembahasan}

Pengeringan daun katang katang menggunankan sinar matahari selama 2 hari sampai daun benar benar kering dan susut pengeringan yang diperoleh sebesar 10\%. Susut pengeringan simplisia daun katang katang sesuai dengan persyaratan simplisia (Anonim, 2016). Hasil dari proses maserasi pembuatan ekstrak daun tapak kuda (Ipomoea pes- caprae L. Sweet) dengan etanol $70 \%$ dapat dilihat pada table 1. Persentase hasil rendaman ekstrak Daun katang katang 
(Ipomoea pes-caprae L. Sweet) dan uji organoleptis diperoleh hasil seperti pada tabel 2 dan tabel 3.

Tabel 1. Hasil Ekstraksi Daun katang katang (Ipomoea pes-caprae L. Sweet)

\begin{tabular}{|l|l|l|}
\hline No & \multicolumn{1}{|c|}{ Jenis } & \multicolumn{1}{c|}{ Jumlah } \\
\hline 1. & Daun tapak kuda kering/ simplisia & 200 gram \\
\hline 2. & Ekstrak cair & $1.100 \mathrm{ml}$ \\
\hline 3. & Ekstrak kental & $85,21 \mathrm{gram}$ \\
\hline
\end{tabular}

Tabel 2. Hasil rendemen ekstrak Daun katang katang (Ipomoea pes-caprae L. Sweet)

\begin{tabular}{|c|lcc|ccc|cc|}
\hline No & $\begin{array}{l}\text { Berat } \\
\text { (gram) }\end{array}$ & simplisia & serbuk & $\begin{array}{l}\text { Berat } \\
\text { (gram) }\end{array}$ & ekstrak & kental & $\begin{array}{l}\% \\
\text { ekstrak }\end{array}$ & rendaman \\
\hline 1. & \multicolumn{3}{|c|}{200} & & \multicolumn{2}{|c|}{42,60} \\
\hline
\end{tabular}

Uji Skrining fitokimia serbuk ekstrak daun katang katang menggunakan metode kualitatif yaitu mereaksikan pereaksi kimia yang sesuai dengan metabolit sekunder flavanoid, alkaloid, tannin dan saponin diperoleh data pada tabel 4. Aktivitas antioksidan dengan metode DPPH menggunakan Vitamin C sebagai kontrol positif (Tabel 5). Dari hubungan antara konsentrasi dan persen inhibisi diperoleh persamaan garis $\mathrm{y}=3,008 \mathrm{x}+50,88$ sehingga diperoleh nilai $\mathrm{IC}_{50}$ sebesar -0,29 yang artinya vitamin C memiliki aktivitas antioksidan yang sangat kuat yaitu < 10 (Tabel 6).

Tabel 3. Hasil uji organoleptis esktrak etanol daun katang katang (Ipomoea Pescaprae L.)

\begin{tabular}{|l|l|}
\hline \multicolumn{1}{|c|}{ Jenis uji organoleptis } & \multicolumn{1}{c|}{ Hasil } \\
\hline Rasa & Sangat pahit sedikit pedas \\
\hline Warna & Hijau tua (kecoklatan) \\
\hline Bau & Khas \\
\hline Tektur & Kasar \\
\hline
\end{tabular}

Tabel 4. Hasil uji skrining Fitokimia Daun katang katang (Ipomoea pes-caprae L. Sweet)

\begin{tabular}{|l|l|c|}
\hline \multicolumn{1}{|c|}{ Jenis Uji } & \multicolumn{1}{|c|}{ Hasil } & Kesimpulan \\
\hline Flavonid & $\begin{array}{l}\text { Terbentuk warna kuning pada } \\
\text { lapisan amil alkohol }\end{array}$ & + \\
\hline Alkaloid & $\begin{array}{l}\text { Terdapat endapan putih } \\
\text { dengan pereskasi meyer }\end{array}$ & + \\
\hline Saponin & $\begin{array}{l}\text { Terbentuk Buih yang stabil } \\
\text { Tanin }\end{array}$ & $\begin{array}{l}\text { Terbentuk warna hijau } \\
\text { kehitaman }\end{array}$ \\
\hline
\end{tabular}


Tabel 5. Persen inhibisi vitamin $\mathrm{C}$ terhadap DPPH

\begin{tabular}{|c|c|c|c|}
\hline No. & Konsentrasi $(\mu \mathrm{g} / \mathrm{mL})$ & Absorbansi. & $\%$ Inhibisi \\
\hline 1 & 2 & 0,096 & 57,52 \\
\hline 2 & 4 & 0,084 & 62,83 \\
\hline 3 & 6 & 0,077 & 65,93 \\
\hline 4 & 8 & 0,048 & 78,76 \\
\hline 5 & 10 & 0,046 & 79,65 \\
\hline
\end{tabular}

Tabel 6. persen penghambatan radikal bebas ekstrak etanol daun katang katang (Ipomoea Pescaprae L.)

\begin{tabular}{|c|c|c|c|c|c|}
\hline Konsentrasi & \multicolumn{4}{|c|}{ Absorbansi } & \multirow{2}{*}{$\begin{array}{c}\% \\
\text { Inhibisi }\end{array}$} \\
\hline Sampel & DPPH & sampel uji + DPPH & sampel uji & selisih & \\
\hline 10 & 0,207 & 0,201 & 0,052 & 0,149 & 28,02 \\
\hline 50 & 0,207 & 0,174 & 0,068 & 0,088 & 57,49 \\
\hline 100 & 0,207 & 0,154 & 0,088 & 0,066 & 68,12 \\
\hline 150 & 0,207 & 0,138 & 0,102 & 0,036 & 82,61 \\
\hline 200 & 0,207 & 0,144 & 0,123 & 0,021 & 89,86 \\
\hline 250 & 0,207 & 0,123 & 0,154 & 0,018 & 91,30 \\
\hline
\end{tabular}

Persamaan regresi linear yang diperoleh dari hubungan konsentrasi ekstrak etanol daun katang katang dengan persen inhibisi adalah $\mathrm{y}=0,248 \mathrm{x}+38,04$ sehingga diperoleh $\mathrm{IC}_{50}$ ekstrak etanol katang katang sebesar 46,774. Artinya daun katang katang dalam etanol memiliki aktivitas antioksidan yang kuat. Hasil penelitian ini sesuai dengan yang pernah dilaporkan oleh (Kathiresan, 2014) bahwa daun katang katang memiliki aktivitas menghambat radikal bebas DPPH sesuai dengan peningkatan konsentrasi. Konsentrasi ekstrak etanol $250 \mu \mathrm{g} / \mathrm{mL}$ memiliki persen penghambatan sebesar 91,30\%, sedangkan yang dilaporkan oleh Kathiresan pada konesntrasi $1000 \mu \mathrm{g} / \mathrm{mL}$ ekstrak metanol memiliki persen penghambatan sebesar 97,85\% dan fraksi ekstrak metanol persen penghambatan sebesar 90,31\% (Gambar 1).

Hasil uji organoleptis pada tabel 3 menunjukkan rasa khas dari serbuk ekstrak etanol yang diperoleh adalah pahit dan terasa pedas sesuai dengan yang dilaporkan oleh Ganjir et al., 2014. Rasa ini dipengaruhi oleh kandungan metabolit sekunder yaitu flavonoid, alkaloid, saponin dan tanin. Kondisi lingkungan tempat tumbuh Ipomoea Pescaprae seperti curah hujan, lama paparan sinar matahari, $\mathrm{pH}$ air laut, kadar garam, dan suhu akan mempengaruhi kandungan fenol dan flavonoid. Senyawa flavonoid merupakan metabolit sekunder yang dihasilkan oleh tumbuhan untuk melindungi diri dari ancaman lingkungan luar seperti hama, serangga, jamur dan perubahan cuaca yang ekstrim sehingga perbedaan kondisi lingkungan menyebabkan perbedaan tingkat stres dan akhirnya mempengaruhi kandungan metabolitnya (Selvam et al., 2015). 
Ipomoea Pescaprae L. Dari pantai tanjung karang pulau lombok memiliki kandungan yang sama dengan yang pernah dilaporkan oleh (Matunog \& Bajo, 2013) yaitu ekstrak etanol Ipomoea Pescaprae mengandung alkaloid, flavonoid streroid, triterpen, tanin dan senyawa fenolik dengan sampel berasal dari Philipina.

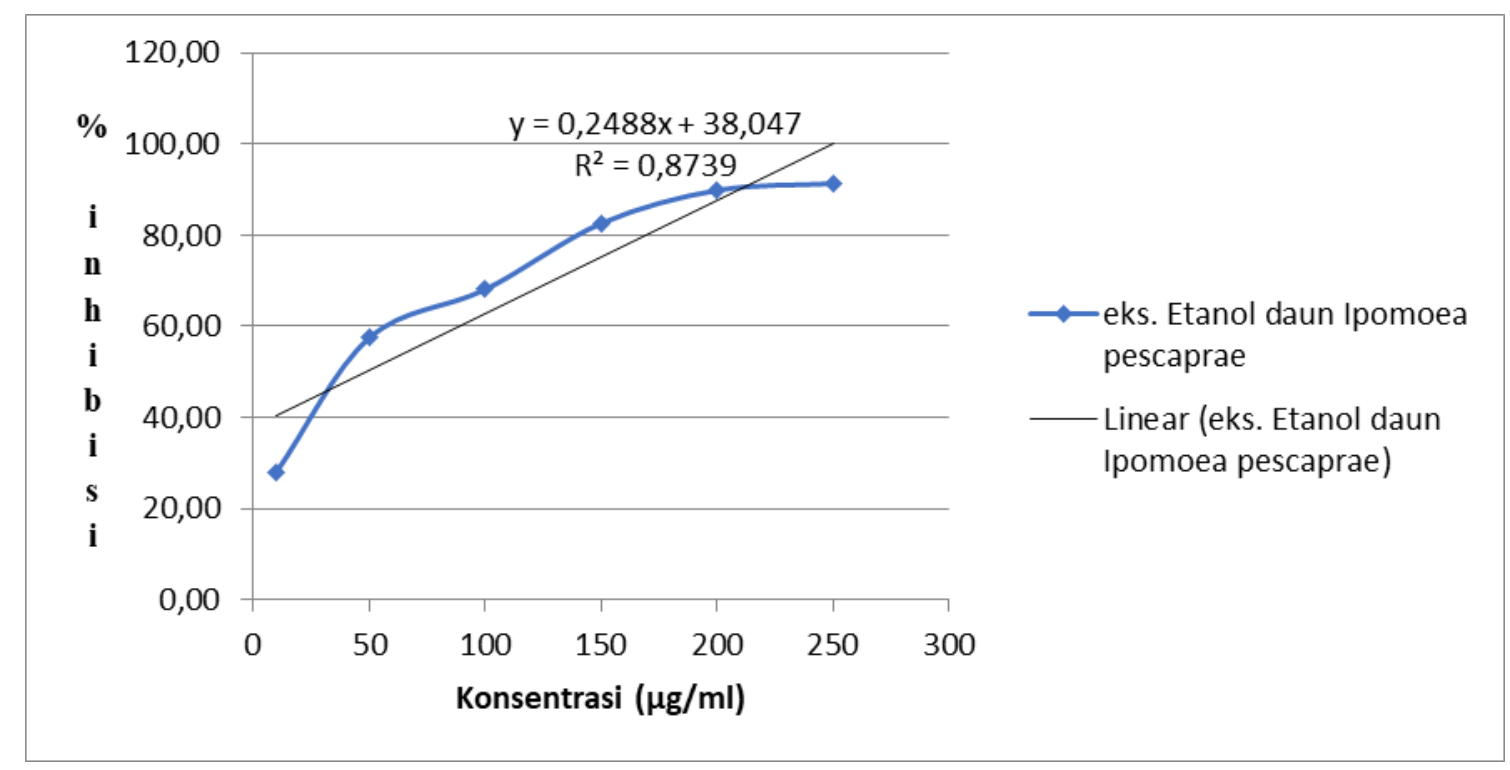

Gambar 1. Grafik hubungan antara konsentrasi ekstrak etanol daun katang-katang (Ipomoea Pescaprae L) dengan persen Inhibisi Radikal Bebas dengan metode DPPH

Senyawa fenolik yang terdapat dalam ekstrak daun katang-katang seperti flavonoid bertanggungjaawab terhadap aktivitas antioksidan ( $\mathrm{Br}$ et al., 2012). Senyawa fenolik, vitamin C, vitamin E, dan beta karoten yang alami terdapat dalam sayur dan buah merupakan senyawa yang dapat mendonorkan elektronnya kepada radikal bebas yang ada di dalam tubuh sehingga bersifat menetralkan dan menjadikan radikal bebas tersebut tidak reaktif lagi (Kumar, Kaur and Jaggi, 2011). Ipomoea Pescaprae memiliki $\mathrm{IC}_{50}$ sebesar 46,774 termasuk dalam kategori kuat dalam menangkal radikal bebas walaupun aktivitas masih lebih rendah dengan vitamin c yang memiliki IC 50 kurang dari 1.Hasil penelitian menunjukkan Semakin tinggi konsentrasi ekstrak semakin besar penghambatan terhadap radikal bebas seperti yang ditunjuukan pada tabel 4. Hasil ini mengindikasikan ada hubungan antara kandungan fenoI dan flavonoid dengan aktivitas antioksidan ((Kumar, Kaur and Jaggi, 2011). Ipomoea potensial untuk dijadikan sumber antioksidan alami (Matunog \& Bajo, 2013).

\section{Kesimpulan}

Dari data hasil penelitian yang telah dilakukan ekstrak etanol Daun katang katang (Ipomoea pes-caprae L. Sweet) dari Pantai Tanjung Karang kota Mataram Nusa Tenggara Barat 
mengandung senyawa metabolite sekunder tannin, saponin, alkaloid dan flavanoid. Ekstrak etanol Daun katang- katang memiliki aktifitas antioksidan yang kuat dengan IC $_{50}$ sebesar 46, 774. Sehingga sangat potensial untuk dikembangkan sebagai obat tradisional sumber antioksidan.

\section{Ucapan Terimakasih}

Terima kasih kepada Direktorat Riset dan Pengabdian Masyarakat (DRPM), Direktorat Jendral penguatan riset dan pengembangan Kementrian Riset, Teknologi, dan Pendidikan Tinggi (KEMENRISTEK DIKTI) yang telah membiayai penelitian ini.

\section{Daftar Pustaka}

Anandhi K., Ushadevi T., 2013, A Study On Antioxidant, Proximate Analysis, Antimicrobial Activity And Phytochemical Analysis Of Ipomoea Pes Caprae By GC-MS. International Journal Of Biotechnology And Alled Fields (IJABF). ISSN : 2320-0774.

Anwar, L., Azmi, J., Herdini, 2015, Potensi tumbuhan akar tapak kuda ( bauhinia hullettii prain) sebagai sumber senyawa antioksidan, Chempublish Journal volume 1 No.1

Br, I. L. R. et al., 2012 ,Antioxidant and Radical Scavenging effect of Ipomoea pes caprae (L.) R. BR, International Journal of PhamTech Research, 4(2), pp. 848-851.

Ganjir, M., Behera, B.R., Bhatnagar, S., 2013, Phytochemical Analysis, Cytotoxic And Antioxidant Potential Ogf Ipomea Pescaprae (L.) R. Br. And Merremia Umbellata (L.) H. Hallier, International Journal Of Scientific And Technology Research, ISSN: 2277-8616, volume 2 (5).

Kathiresan, S. K., 2014, Antioxidant and Free Radical Scavenging Activities of Ipomoea pescaprae (L.) R. Br. Extracts, International Journal of Current Pharmaceutical Review anda Research, 5(4), pp. 91-109.

Kumar, T., Kaur, C. and Jaggi, S., 2011, Antioxidant activity and phenolic content in genotypes of Indian jujube ( Zizyphus mauritiana Lamk .), ARABIAN JOURNAL OF CHEMISTRY. King Saud University. doi: 10.1016/j.arabjc.2011.11.005.

Mag, P. et al., 2015, In vivo antitumor potential of Ipomoea pes - caprae on melanoma cancer, 11(42). doi: 10.4103/0973-1296.153099.

Matunog, V.E., Bajo, L.M., 2013, Phytochemical Screening and antioxidant Potential of " Beach Morning Glory" Ipomoea Pescaprae (L.) Roth Leave Extract, Journal Multidisiplinary Studies Vol. 1, No. 1, ISSN: 2350-7020 1-18

Pongproyoon U., Bohlin L., 1991, antiinflamatory activity of Ipomoea Pescaprae (L.) R. Br., Phytoterapi resarch, Vol 5, No. 2.63-66

Selvam, N. T. and Acharya, M. V., 2015, Review of Ipomoea pes-tigridis L . : Traditional Uses , Botanical Characteristics, Chemistry and Biological Activities', 6(12), pp. 1443-1448.

Suhasini, S., Elanchezhiyan, C. and Babby, A., 2014, Hepatoprotective Effect Of Ipomoea PesCaprae Leaves Extract In Streptozotocin Induced Diabetic Rats', International Journal of Pharmacy and Pharmaceutical science research, 4(2), pp. 27-30.

Vieira, D., Padoani, C., Soares, J.S., Adriano, J., Vilho, F.C., Souza, M.M., Bresolin, T.M.B., Couto, A. G., 2013, Development of hydroethanolic extract of Ipomoea Pescaprae using factorial design follwe by antinociceptive and antiinflamatory evaluation, Brazilian Journal of Pharmacognosy, 23(91), pp. 72-78. 